\title{
Diagnosis of fish and shellfish allergies
}

This article was published in the following Dove Press journal:

Journal of Asthma and Allergy

\section{Wai Sze Tongl,* \\ Agatha WT Yuen ${ }^{1, *}$ \\ Christine YY Wai ${ }^{2}$ \\ Nicki YH Leung ${ }^{2}$ \\ Ka Hou Chu' \\ Patrick SC Leung ${ }^{3}$}

'School of Life Sciences, The Chinese University of Hong Kong, Shatin, Hong Kong, SAR, China; ${ }^{2}$ Department of Paediatrics, Faculty of Medicine, The Chinese University of Hong Kong, Hong Kong, SAR, China; ${ }^{3}$ Division of Rheumatology, Allergy and Clinical Immunology, School of Medicine, University of California Davis, Davis, CA, USA

*These authors contributed equally to this work
Correspondence: Christine YY Wai Department of Paediatrics, Faculty of Medicine, The Chinese University of Hong Kong, 6/F, Lui Che Woo Clinical Sciences Building, Prince of Wales Hospital, Shatin, N.T., Hong Kong, SAR, China

Tel +85235052829

Fax +852 26360020

Email christineyywai@cuhk.edu.hk

Patrick SC Leung

Division of Rheumatology, Allergy and Clinical Immunology, University of California at Davis School of Medicine, 45I Health Sciences Drive, Suite 6510, Davis, CA 95616, USA

$\mathrm{Tel}+\mathrm{I} 5307544943$

Fax + I 5307546047

Email psleung@ucdavis.edu

\begin{abstract}
Seafood allergy is a hypersensitive disorder with increasing prevalence worldwide. Effective and accurate diagnostic workup for seafood allergy is essential for clinicians and patients. Parvalbumin and tropomyosin are the most common fish and shellfish allergens, respectively. The diagnosis of seafood allergies is complicated by cross-reactivity among fish allergens and between shellfish allergens and other arthropods. Current clinical diagnosis of seafood allergy is a complex algorithm that includes clinical assessment, skin prick test, specific IgE measurement, and oral food challenges. Emerging diagnostic strategies, such as component-resolved diagnosis (CRD), which uses single allergenic components for assessment of epitope specific IgE, can provide critical information in predicting individualized sensitization patterns and risk of severe allergic reactions. Further understanding of the molecular identities and characteristics of seafood allergens can advance the development of CRD and lead to more precise diagnosis and improved clinical management of seafood allergies.
\end{abstract}

Keywords: skin prick test, DBPCFC, component-resolved diagnosis, immunoCAP, ISAC

\section{Introduction}

IgE-mediated food allergy is a major global public health issue. A cross-sectional study in a United States cohort of 333,200 children reported a food allergy prevalence of $6.7 \% .{ }^{1}$ Sensitization usually occurs by exposure through ingestion, inhalation, or skin contact, and re-exposure to milligrams of allergens is sufficient to trigger life-threatening allergic responses. ${ }^{2,3}$ Another survey in the United States on 38,480 subjects younger than 18 years of age reported a food allergy prevalence of $8.0 \%$, where $38.7 \%$ of the cohort experienced severe allergic reaction, and 30.4\% developed multiple food allergies. ${ }^{4}$

Fish and shellfish are among the most common culprits of food allergies. Fish allergy affects $0.2 \%$ of the general population. ${ }^{5}$ In the USA, the lifetime prevalence rate for reported fish allergy was $0.4 \%$ while $0.2 \%$ of population experienced both fish and shellfish allergy. ${ }^{6}$ In Asia, fish allergy prevalence was much higher in the Philippines $(2.29 \%)$ than in Singapore $(0.26 \%)$ and Thailand $(0.29 \%){ }^{7}$ Worldwide prevalence of shellfish allergy was found to be $0.6 \%$ with higher incidence reported in the Asia-Pacific region. ${ }^{8}$ In the USA, the lifetime prevalence rate for reported shellfish allergy was $2 \%$, with higher prevalence reported in adults $(2.8 \%)$ compared to children $(0.6 \%)$, and in women $(3.6 \%)$ compared to men $(2 \%) .{ }^{6}$ Shellfish allergy is highly prevalent among teenagers in the Philippines (5.12\%) and Singapore (5.23\%) and is the leading cause of food anaphylaxis in Hong Kong and Taiwan..$^{9-11}$ The increasing incidence of fish and shellfish allergy may be attributed to the growing consumption of seafood worldwide. The 
2016 Food and Agriculture Organization of the United Nations report indicated that global fish consumption per capita has risen to over $20 \mathrm{~kg}$ year on year. ${ }^{12}$ In 2014 , the global capture fisheries production was 93.4 million tons, while crustacean and mollusks output from aquaculture amounted to 6.9 and 16.1 million tons, respectively. ${ }^{12}$

Considering the pervasiveness of fish and shellfish allergies, developing precise diagnostic protocols is essential for appropriate prevention and management strategies including avoidance of unnecessary dietary restrictions. Conventional first-line diagnostic approach includes clinical assessment, oral food challenge (open or blinded), skin prick test (SPT), and serum-specific IgE (sIgE) measurement. Fish and shellfish extracts are commonly used in these in vivo and in vitro tests. However, the presence of cross-reactive allergens and the varying allergen contents among commercial extracts may lead to over- or underdiagnosis of seafood allergy. Fortunately, our increasing understanding of seafood allergens and improvements in technology to produce recombinant allergens allow for the detection of allergen-specific $\operatorname{IgE}$ and the development of component-resolved diagnosis (CRD) to reduce the ambiguities of conventional tests.

\section{Fish allergens and cross-reactivity}

Twenty-one allergens from 15 fish species are officially recognized by the World Health Organization/International Union of Immunological Societies at present (Table 1). Parvalbumin was first identified as the major fish allergen in $1969 .{ }^{13}$ It is a $10-12 \mathrm{kDa}$ protein abundant in muscle and is physiologically important for calcium binding. Bugajska-Schretter et al characterized the $\mathrm{IgE}$ reactive proteins in fish with serum samples from 30 fish-allergic patients and demonstrated that all tested sera were IgE positive to parvalbumin from cod extract (Gad c 1). ${ }^{14}$ Interestingly, calcium depletion reduced IgE binding to parvalbumin in most patient sera. ${ }^{14}$ Fish parvalbumin is thermally stable ${ }^{15}$ and maintains its allergenic activity and antigenicity even under acidic conditions and after pepsinolysis. ${ }^{13,16}$ Short burst swimming in fish is powered by white muscles, which have a higher parvalbumin content than the dark muscles that drives continuous stroke. ${ }^{17}$ It was, therefore, suggested that fish with more dark muscles such as tuna and mackerel is less allergenic than fish with more white muscle such as cod and haddock. ${ }^{17}$ Based on amino acid sequences, the parvalbumin protein family can be classified into the less acidic alpha-subtype (nonallergenic) or the more acidic beta-subtype (allergenic). ${ }^{18-20}$ Fish contain mainly beta-subtype parvalbumins while the alpha-subtype is found in other vertebrates. ${ }^{21}$

In 2000, fish gelatin was discovered as a fish allergen, and in 2013 , Kuehn et al reported the $50 \mathrm{kDa}$ beta-enolase and 40 $\mathrm{kDa}$ fructose-bisphosphate aldolase $\mathrm{A}$ from cod, salmon, and tuna as important fish allergens. ${ }^{22-26}$ Specific IgE to enolases, adolases, and gelatin was detected in $62 \%, 50 \%$, and $19.3 \%$ of fish-allergic subjects, respectively. ${ }^{23}$ Fish gelatin was reported

Table I Fish allergens with approved nomenclature by the World Health Organization and International Union of Immunological Societies (www.allergen.org)

\begin{tabular}{|c|c|c|c|c|}
\hline Allergen & Species & Allergen name & Molecular weight (kDa) & Reference \\
\hline \multirow[t]{13}{*}{ Beta-parvalbumin } & Clupea harengus & Clu h I & 12 & 127 \\
\hline & Cyprinus carpio & Сур с I & 12 & 128 \\
\hline & Gadus callarias & Gad c I & 12 & 14 \\
\hline & Gadus morhua & Gad m I & 12 & 129 \\
\hline & Lates calcarifer & Lat c I & 11.5 & 130 \\
\hline & Lepidorhombus whiffiagonis & Lep w I & 11.5 & 15 \\
\hline & Oncorhynchus mykiss & Onc m I & 12 & $13 \mid$ \\
\hline & Rastrelliger kanagurta & Ras k I & 11.3 & 132 \\
\hline & Salmo salar & Sal s I & 12 & 133 \\
\hline & Sardinops sagax & Sar sa I & 12 & 134 \\
\hline & Sebastes marinus & Sub m I & 11 & 135 \\
\hline & Thunnus albacares & Thu a I & 11 & 34 \\
\hline & Xiphias gladius & Xip g I & II.5 & 136 \\
\hline \multirow[t]{3}{*}{ Beta-enolase } & G. morhua & Gad m 2 & 47.3 & 23 \\
\hline & S. salar & Sal s 2 & 47.3 & 23 \\
\hline & T. albacares & Thu a 2 & 50 & 23 \\
\hline \multirow[t]{3}{*}{ Aldolase A } & G. morhua & Gad m 3 & 40 & 23 \\
\hline & S. salar & Sal s 3 & 40 & 23 \\
\hline & T. albacares & Thu a 3 & 40 & 23 \\
\hline Tropomyosin & Oreochromis mossambicus & Ore m 4 & 33 & 22 \\
\hline Beta-prime-component of vitellogenin & Oncorhynchus keta & Onc k 5 & 18 & 137 \\
\hline
\end{tabular}


to trigger positive response in SPT in $10 \%$ of fish-allergic patients but oral food challenge with a cumulative dose of $3.61 \mathrm{~g}$ of gelatin did not trigger adverse reactions in any of the allergic subjects, thus raising the question if gelatin is a clinically relevant fish allergen. ${ }^{27}$ Furthermore, it was reported that a minority of fish-allergic patients developed SIgE to other fish allergens such as aldehyde phosphate dehydrogenase from cod fish, ${ }^{28,29}$ triose-phosphate isomerase, and serum albumin from amago salmon ${ }^{30}$ and creatine kinase from tuna. ${ }^{31}$

Clinical cross-reactivity among various fish species is common even in fishes from taxonomically distinct orders. ${ }^{32-34}$ Parvalbumin from cod extract ( Gad c 1) has been shown to cross-react with parvalbumin homologs from distantly related species such as wolffish or flounder. ${ }^{14,34-37}$ Besides parvalbumin, cross-reactivity between fish muscle collagens from five fish species has also been reported. ${ }^{25-29}$ However, in some cases, codfish-allergic patients may ingest other fish without triggering allergic symptoms. ${ }^{32,35,38}$ In addition to the cross-reactivity among fishes, clinical cross-reaction of parvalbumin between fish and other vertebrate meats has been described. Serologic cross-reactions have been described between fish and frog beta-parvalbumins. ${ }^{39}$ Cross-reactivity among fish and chicken allergens including parvalbumins, enolases, and aldolases have been reported, ${ }^{40}$ and described as "fish-chicken syndrome" phenomenon.

\section{Shellfish allergens and cross- reactivity}

Compared with that of fish allergens, the spectrum of shellfish allergens is more diverse (Table 2). ${ }^{41,42}$ Tropomyosin (TM) was identified as the major shrimp allergen in $1993 .{ }^{43} \mathrm{TM}$ is a protein of $38-41 \mathrm{kDa}$ with coiled-coiled secondary structure and is highly conserved across invertebrates to regulate muscle contraction. ${ }^{44} \mathrm{TM}$ is a heat-stable allergen that can withstand high temperature and common food processing. ${ }^{42}$ Usui et al examined the structural stability of shellfish TM and showed that the alpha-helical structure of TM collapsed easily upon heating to $80^{\circ} \mathrm{C} .{ }^{45}$ However, TM could regain its native circular dichroism pattern and retained its antigenicity after cooling to $25^{\circ} \mathrm{C}$. ${ }^{45}$ Furthermore, TM can be easily solubilized and can remain at high concentration even after thorough cooking, such as boiling and roasting. ${ }^{46}$

Other shellfish allergens have also been well characterized. Arginine kinase (AK) was identified as a shrimp allergen with $\operatorname{IgE}$ reactivity that induced immediate skin manifestation in sensitized patients. ${ }^{47}$ Although AK is abundant in shrimp muscle, unlike TM, AK is physiochemically and thermally unstable. ${ }^{48,49}$ Significant IgE reactivity to AK (Pen $\mathrm{m} 2$ ) was reported in $27 \%$ of shrimp-allergic patients. ${ }^{47}$ Myosin light chain (MLC) is a $20 \mathrm{kDa}$ allergen displaying IgE reactivity in both raw and cooked shrimp extracts despite the alteration in its secondary structure under high temperature or acid treatment. ${ }^{50,51}$ Sarcoplasmic calcium-binding protein (SCP) is an allergen recognized by serum $\operatorname{IgE}$ in $38 \%$ of patients with shrimp allergy. ${ }^{52}$ Similar to other allergenic components, SCP is highly conserved among crustaceans (alpha chain: 90\%-94\% identity, beta chain: $80 \%$ identity).$^{53} \mathrm{IgE}$ reactivity to shrimp hemocyanin, troponin $\mathrm{C}$, paramyosin, troponin I, triose phosphate isomerase, myosin heavy chain, alpha-actinin, smooth endoplasmic reticulum $\mathrm{Ca}^{2+}$ ATPase, and GADPH has been reported, but their clinical significance in food allergies is less understood. ${ }^{54-58}$ Although TM, AK, and SCP were well characterized as crab allergens, TM is the only allergen identified across multiple edible crustacean and mollusk species. ${ }^{59,60}$ There remains a clear need to compile a comprehensive shellfish allergen panel.

The major shellfish allergen, TM, has been suggested as a pan-allergen, whose cross-reactivity is likely because of the high homology in amino acid sequence (69\%-100\%) among crustaceans and mollusks. ${ }^{61}$ Although crustacean and cephalopod TMs share only 63\%-64\% sequence identity, their cross-reactivity is probably due to their highly conserved IgE-binding epitopes. ${ }^{62}$ Nevertheless, there are also reports on species-specific allergies to marine shrimp (Penaeus monodon) or fresh water shrimp (Macrobrachium rosenbergii) through oral challenge. ${ }^{63}$ Apart from the cross-reactivity observed among edible shellfish, Leung et al also reported significant $\operatorname{IgE}$ reactivity of sera from shrimp-allergic subjects to grasshopper, cockroach, and fruit fly. ${ }^{64}$ Cross-reactivity between shrimp and cockroach is also experimentally demonstrated in other studies. ${ }^{65,66}$ Reciprocally, subjects with house dust mite or cockroach allergy also showed substantial IgE reactivity to shrimp TM. ${ }^{65-67}$ The IgE cross-reactivity among TMs might be attributed to the recognition of similar epitopes within the eight IgE binding epitopes in shrimp TM (Pen a 1), of which five are identical to cockroach TM (Per a 7), and four are identical to lobster TM (Hom a 1) and dust mite TM (Der p 10 and Der f 10). ${ }^{65}$ Besides TM, Gámez et al also reported that ubiquitin, alpha-actinin, and $\mathrm{AK}$ are responsible for miteseafood cross-reactivity, ${ }^{41}$ and a similar study by Pascal et al also suggested that $\mathrm{AK}$ and hemocyanin may be the markers of cross-reactivity between shellfish and other arthropods. ${ }^{68}$

\section{Cross-reactivity between fish and shellfish}

To date, limited cases of cross-reactivity between fish and shellfish allergens have been reported ${ }^{69}$ with most of these studies suggesting TM as the possible cross-reactive allergen. 
Table 2 Officially recognized shellfish allergens with approved nomenclature by the World Health Organization and International Union of Immunological Societies (www.allergen.org)

\begin{tabular}{|c|c|c|c|c|}
\hline Allergen & Species & Allergen Name & MW & Reference $^{\mathrm{a}}$ \\
\hline \multirow[t]{19}{*}{ Tropomyosin } & Charybdis feriatus & Cha f I & 34 & 60 \\
\hline & Crangon crangon & Cra c I & 38 & 55 \\
\hline & Crassostrea gigas & Cra g I & 18 & 153 \\
\hline & Haliotis laevigata $\times$ Haliotis rubra & Hall I & 33.4 & \\
\hline & Helix aspersa & Hel as I & 36 & 154 \\
\hline & Homarus americanus & Hom a I & 34 & 138 \\
\hline & Litopenaeus vannamei & Lit $\vee \mathrm{I}$ & 36 & 139 \\
\hline & Macrobrachium rosenbergii & Mac r I & 37 & 140 \\
\hline & Melicertus latisulcatus & Mel I I & 38 & $|4|$ \\
\hline & Metapenaeus ensis & Met e I & 34 & 142 \\
\hline & Pandalus borealis & Pan b I & 37 & 87 \\
\hline & Panulirus stimpsoni & Pan s I & 34 & 138 \\
\hline & Penaeus aztecus & Pen a I & 36 & 143 \\
\hline & Penaeus indicus & Pen i I & 34 & 43 \\
\hline & Penaeus monodon & Pen m I & 38 & 144 \\
\hline & Portunus pelagicus & Por $\mathrm{p} I$ & 39 & 49 \\
\hline & Procambarus clarkii & Pro c I & 36 & \\
\hline & Saccostrea glomerata & Sac g I & 38 & 155 \\
\hline & Todarodes pacificus & Tod p I & 38 & 156 \\
\hline \multirow[t]{5}{*}{ Arginine kinase } & Crangon crangon & Cra c 2 & 45 & 55 \\
\hline & Litopenaeus vannamei & Lit v 2 & 40 & 145 \\
\hline & Penaeus monodon & Pen $\mathrm{m} 2$ & 40 & 47 \\
\hline & Procambarus clarkii & Pro c 2 & 40 & 157 \\
\hline & Sylla paramamosain & Scy p 2 & 40 & 158 \\
\hline \multirow[t]{3}{*}{ Myosin light chain 2} & Homarus americanus & Hom a 3 & 23 & 146 \\
\hline & Litopenaeus vannamei & Lit $\vee 3$ & 20 & 50 \\
\hline & Penaeus monodon & Pen $\mathrm{m} 3$ & 20 & 144 \\
\hline \multirow[t]{5}{*}{ Sarcoplasmic calcium binding protein } & Crangon crangon & Cra c 4 & 25 & 55 \\
\hline & Litopenaeus vannamei & Lit $\vee 4$ & 20 & 52 \\
\hline & Penaeus monodon & Pen m 4 & 20 & 147 \\
\hline & Pontastacus leptodactylus & Pon I 4 & 24 & \\
\hline & Sylla paramamosain & Scy $\mathrm{P} 4$ & 20 & 159 \\
\hline \multirow[t]{3}{*}{ Myosin, light chain I } & Artemia franciscana & Art fr 5 & 17.5 & \\
\hline & Crangon crangon & Cra c 5 & 17.5 & 55 \\
\hline & Procambarus clarkii & Pro c 5 & 18 & 51 \\
\hline \multirow[t]{3}{*}{ Troponin C } & Crangon crangon & Cra c 6 & 21 & 55 \\
\hline & Homarus americanus & Hom a 6 & 20 & 146 \\
\hline & Penaeus monodon & Pen m 6 & 16.8 & 160 \\
\hline Troponin I & Pontastacus leptodactylus & Pon I 7 & 30 & 148 \\
\hline \multirow[t]{4}{*}{ Triosephosphate isomerase } & Archaeopotamobius sibiriensis & Arc s 8 & 28 & \\
\hline & Crangon crangon & Cra c 8 & 28 & 55 \\
\hline & Procambarus clarkii & Pro c 8 & 28 & 161 \\
\hline & Sylla paramamosain & Scy p 8 & 28 & \\
\hline Ovary development-related protein & Eriocheir sinensis & Eris 2 & 28.2 & 149 \\
\hline
\end{tabular}

Note: ${ }^{a}$ The corresponding allergens of the empty spaces remaining were approved by the World Health Organization and International Union of Immunological Societies with unpublished data.

In 2013, Liu et al demonstrated that sera from tilapia-allergic subjects $(10 / 10)$ reacted to a $32 \mathrm{kDa}$ protein that was later identified as TM. ${ }^{69}$ Interestingly, there is $87.7 \%$ amino acid sequence homology between TM from tilapia and human but only $58.8 \%$ homology between the tilapia and northern shrimp (Pandalus borealis) TM. Further, this study also pointed out that antibodies against human TM isoform 5 could be present in patients with inflammatory bowel disease (IBD). It is intriguing that six out of ten of the tilapia-allergic subjects included in this study were diagnosed with IBD, bringing to question whether the detected reactivity was a consequence of allergy or autoimmunity. $22,70,71$

On the other hand, Peixoto et al illustrated IgE reactivity among TMs from hake, codfish, shrimp, and Indian prawn in the serum of an 11-year-old boy in Spain by IgE immunoblotting and competitive-inhibition immunoblotting. As the specific IgE level to crustaceans $(>100 \mathrm{kUA} / \mathrm{L})$ was markedly higher than to fishes $(0.02-2.77 \mathrm{kUA} / \mathrm{L})$ accord- 
ing to ImmunoCAP, the authors suggested shrimp TM as the primary sensitizer, while reaction with fish TM was a consequence of cross-reactivity in this subject. However, it was clearly reported in this study that this 11-year-old boy had previous experience of fish allergy that apparently occurred before the episode of shrimp anaphylaxis. It was also his first time consuming shrimp when he was admitted to hospital during an anaphylaxis. ${ }^{69}$ Nevertheless, we cannot conclude yet whether cross-reactivity between fish and shellfish, and specifically among their TMs, exists based on these two studies.

\section{Diagnosis of fish and shellfish allergies}

The current clinical approaches to seafood allergy diagnosis include clinical assessment, SPT, sIgE testing, and oral food challenge. A suggested algorithm is illustrated in Figure 1. The emerging and promising strategy of CRD is also considered here.

\section{Clinical assessment}

Clinical assessment is the first step of allergy diagnosis. Clinical symptoms and medical history underpin the likelihood of seafood allergy. For accurate diagnosis, information is collected on allergic episodes, including the type and quantity of suspected seafood ingested, the time to onset of symptoms, whether previous exposure to suspected culprits elicited similar allergic responses, and when the last reaction to food occurred. ${ }^{72}$ As shellfish is recognized as one of the major food groups to induce food-dependent exercise-induced anaphylaxis, ${ }^{73}$ whether exercise was performed before an allergic episode should also be considered. Family history of food allergy is often considered during clinical assessment. However, the link between genetics and seafood allergy has not been thoroughly established, with only one report of an estimated heritability of 0.54 in a twin study on shellfish allergy. ${ }^{74}$

One major drawback with clinical assessments is that patients often cannot provide precise and detailed medical histories and may fail to identify the suspected food that trigger their allergic symptoms. ${ }^{75}$ It is also crucial that the history is assessed by an allergist capable of differentiating other disorders with similar clinical presentations that might be misconstrued as food allergy. Additional tests, such as SPT, sIgE levels, and/or results of oral food challenge, are usually interpreted in conjunction before reaching a diagnosis.

\section{SPT}

SPT is a common in vivo screening procedure for IgEmediated food hypersensitivity by examining skin reactivity to food extracts. It is a reliable method for patients to rapidly

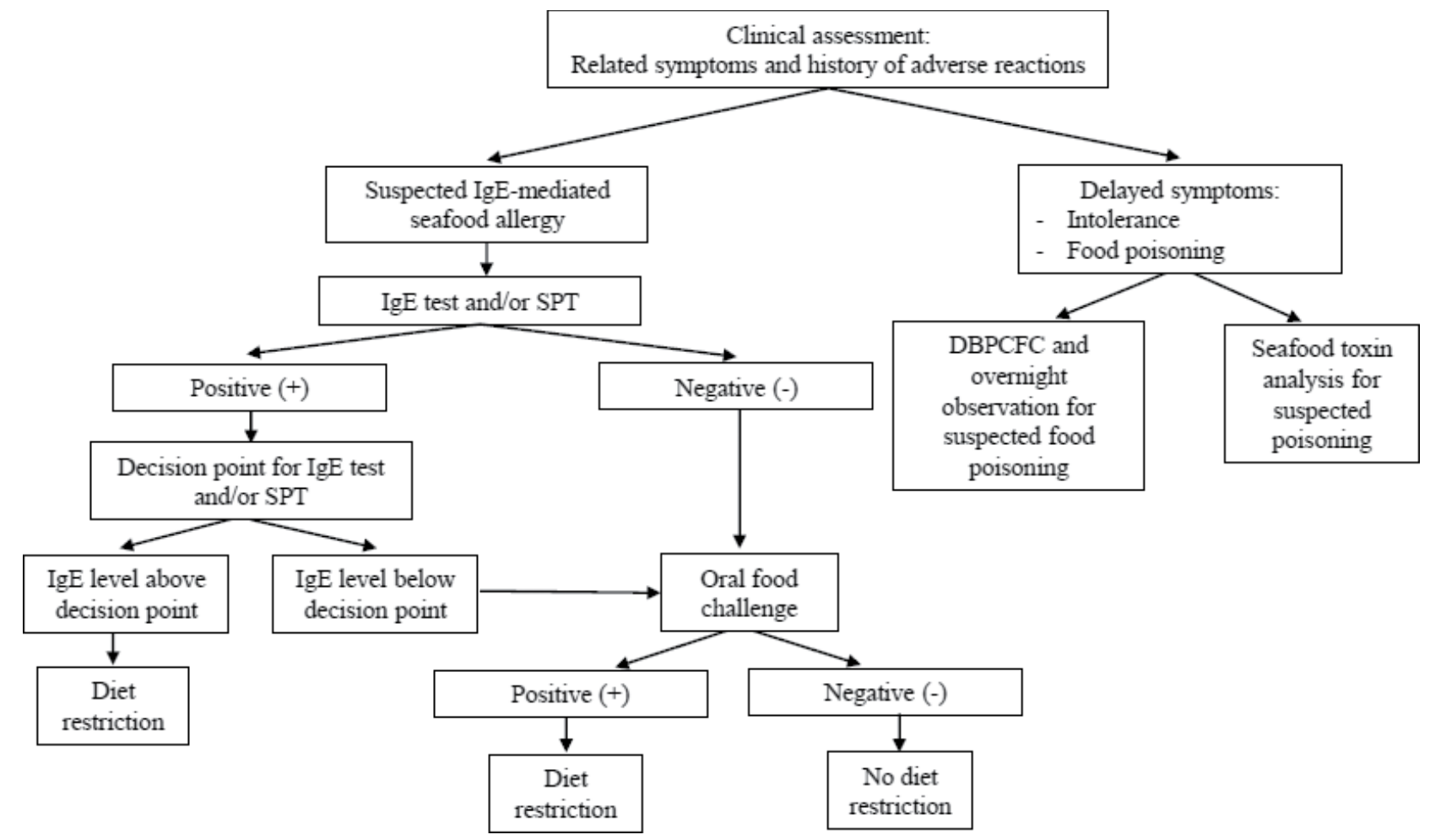

Figure I Diagnostic algorithm and clinical management for seafood allergy.

Note: Data from Niggemann and Beyer ${ }^{150}$ and Lopata et al. ${ }^{151}$

Abbreviations: DBPCFC, double-blind placebo-controlled food challenge; lgE, immunoglobulin E; SPT, skin prick test. 
determine their sensitization results and can be tested with uncommon allergens that are not available as commercial extracts. The cross-linking of specific IgE with allergens introduced into the skin triggers an immunologic milieu, leading to the release of various mediators including histamine, which is responsible for localized swelling around the prick area.

The procedure for SPT involves applying a drop of allergen test solutions to the forearm or back along with positive (histamine $1-10 \mathrm{mg} / \mathrm{mL}$ ) and negative (50\% glycerol saline) control drops. Modified methods may apply a lancet aid allergen penetration. Localized wheals are quantified by measuring the mean of the longest diameter and the length of the perpendicular line through its middle after 15-30 minutes of skin pricking. According to European standards, positive reactions are defined by wheal sizes from test drops that are more than $3 \mathrm{~mm}$ greater in diameter than those from the negative control. ${ }^{76,77}$ SPT requires normal healthy skin with good patient cooperation. Drugs that may interfere with skin reactivity (eg, antihistamine, phenothiazines, and antidepressants) must be avoided before SPT. However, the safety of SPT for seafood allergy has not been fully evaluated. Cases of SPT-induced anaphylaxis and fatality have been reported after application of fish, egg, shellfish nut, and peanut allergens. ${ }^{78,79}$ Although the risk associated with SPT is minimal, anaphylactic precautions must be in place.

Although SPT is a more sensitive test method for fish allergy than milk, egg, and peanut allergies, ${ }^{80}$ commercially available fish and shellfish extracts are limited compared to the wide variety of dietary fish and shellfish. Prick-to-prick tests using fresh food could, in this regard, circumvent the obstacle. ${ }^{81,82}$ The reliability of SPT could be greatly ham- pered by the method of SPT and measurement method, as well as the lack of allergen standardization and presence of preservatives in the extracts. ${ }^{83-86}$ A study by Asero et al on five commercial crustacean SPT extracts found that these commercial extracts displayed a dramatic loss of protein bands compared to fresh shrimp extract on sodium dodecyl sulfate polyacrylamide gel electrophoresis (SDS-PAGE), which could cause heterogeneous SPT profiles. Attention should, thus, be drawn to the diagnostic sensitivity of SPT depending on the commercial extract used.

Recombinant allergens that can be standardized of its quantity and quality could be an alternative. For example, recombinant Pan b 1 was found to induce equivalent positive wheal sizes as natural Pan b 1 and commercial shrimp extract. ${ }^{87}$ The drawback with these recombinant proteins, however, is that other potentially important allergens from natural extracts will be excluded. Recombinant allergens also do not address cross-reactivity when identifying a bona fide allergen. Future analyses evaluating the diagnostic utility of fish and other shellfish components in SPT are expected.

\section{Specific lgE measurement}

Serologic sIgE level is useful not only for diagnosis, but also for predicting the development of tolerance and persistence of seafood allergy, as well as monitoring allergy treatments. ${ }^{88}$ Common clinically adopted sIgE measurement platforms include HYPEC-288 (Hycor-Agilent), Immunulite (Siemens), and the ImmunoCAP (Phadia). ${ }^{89}$ In the ImmunoCAP system, 16 shellfish extracts and 28 fish extracts are readily available for routine sIgE quantification (Tables 3 and 4), but allergen components are scarce.

Table 3 Common crustacea and mollusca allergens included in the ImmunoCAP system (Phadia/Thermo Fisher Scientific) (http://www. phadia.com/en/Products/Allergy-testing-products/ImmunoCAP-Allergen-Information/Food-of-Animal-Origin/Shellfish/Shrimp/)

\begin{tabular}{|c|c|c|c|}
\hline Taxa & Food groups (test code) & Commercial allergens & Source \\
\hline \multirow[t]{8}{*}{ Crustacea } & Shrimp (f24) & Metapenaeopsis barbata & Boiled, frozen, or raw, frozen meat \\
\hline & & Metapenaus joyneri & Boiled, frozen, or raw, frozen meat \\
\hline & & Pandalus borealis & Boiled, frozen, or raw, frozen meat \\
\hline & & Penaeus monodon & Boiled, frozen, or raw, frozen meat \\
\hline & Lobster & Crayfish (f320): Astacus astacus & Unknown \\
\hline & & Lobster (f80): Homarus gammarus & Unknown \\
\hline & & Langust (f304): Palinurus spp. & Boiled meat and shell \\
\hline & Crab (f23) & Chionocetes spp. & Boiled meat \\
\hline \multirow[t]{8}{*}{ Mollusca } & Abalone (f346) & Haliotis spp. & Unknown \\
\hline & Blue mussel (f37) & Mytilus edulis & Canned meat \\
\hline & Clam (f207) & Clam & Fresh frozen muscle \\
\hline & Octopus (f59) & Octopus vulgaris & Fresh frozen muscle \\
\hline & Oyster (f290) & Ostrea edulis & Fresh whole oyster \\
\hline & Scallop (f338) & Pecten spp. & Squid muscle \\
\hline & Pacific flying squid (f58) & Todarodes pacificus & Squid meat \\
\hline & Squid (f258) & Loligo edulis, Loligo vulgaris & Unknown \\
\hline
\end{tabular}


Table 4 Common fish allergens included in the ImmunoCAP system (Phadia/Thermo Fisher Scientific) (http://www.phadia.com/en/ Products/Allergy-testing-products/ImmunoCAP-Allergen-Information/Food-of-Animal-Origin/Fish/Anchovy/)

\begin{tabular}{|c|c|c|}
\hline Food groups (test code) & Commercial allergens & Source \\
\hline Anchovy (f3|3) & Engraulis encrasicolus & Whole fish \\
\hline Catfish (f369) & Ictalurus punctatus & Fish filet \\
\hline Chub mackerel (f50) & Scomber japonicas & Fish muscle \\
\hline $\operatorname{Cod}(\mathrm{f} 3)$ & Gadus morhua & Fish muscle \\
\hline Eel (f264) & Anguilla Anguilla & Whole fish \\
\hline Grouper (f4l0) & Epinephelus sp. & Fish filet \\
\hline Gulf flounder ( $f \mid 47)$ & Paralichthys albigutta & Fish filet \\
\hline Haddock (f42) & Melanogrammus aeglefinus & Whole fish \\
\hline Hake (f307) & Merluccius merluccius & Fish muscle \\
\hline Halibut (f303) & Hippoglossus hippoglossus & Fish muscle \\
\hline Herring (f205) & Clupea harengus & Fish muscle \\
\hline Jack mackerel/Scad (f60) & Trachurus japonicas & Fish muscle \\
\hline Mackerel (f206) & Scomber scombrus & Fresh meat \\
\hline Megrim (f3II) & Lepidorhombus whiffiagonis & Whole fish \\
\hline Orange roughy (f4|2) & Hoplostethus atlanticus & Fish filet \\
\hline Plaice (f254) & Pleuronectes platessa & Fish muscle \\
\hline Pollock (f4I3) & Pollachius virens & Fish filet \\
\hline Red snapper (f38I) & Lutjanus campechanus & Whole fish \\
\hline Salmon, Atlantic (f4I) & Salmo salar & Fish muscle \\
\hline Sardine (Pilchard) (f308) & Sardine pilchardus & Whole fish \\
\hline Sardine/Japanese pilchard (f6I) & Sardinops melanosticta & Fish muscle \\
\hline Sole (f337) & Solea solea & Fish muscle \\
\hline Swordfish (f3|2) & Xiphias gladius & Fish muscle \\
\hline Tilapia (f4|4) & Oreochromis sp. & Fish filet \\
\hline Trout, Rainbow trout (f204) & Oncorhynchus mykiss & Fish muscle \\
\hline Tuna or Yellow fin (f40) & Thunnus albacares & Fish muscle \\
\hline Walleye pike (f4I5) & Sander vitreus (Stizostedion vitreum) & Fish filet \\
\hline Whitefish (Inconnu) (f384) & Stenodus sp. & Fish filet \\
\hline
\end{tabular}

It is generally believed that the levels of SIgE and the severity of allergic symptoms, ${ }^{73}$ or the outcome of food challenge, are closely associated. ${ }^{90}$ Mekaroonkamol et al also showed that measuring shrimp sIgE could be a useful screening test with high sensitivity (90\%) and high positive predictive value (PPV; 0.86), ${ }^{91}$ while individuals with serologic cod sIgE levels higher than $20 \mathrm{kUA} / \mathrm{L}$ would give at least $95 \%$ certainty of positive food challenge results. ${ }^{92,93}$ However, the extensive IgE cross-reactivity among shrimp, cockroach, and dust mites could misrepresent the association between a positive shellfish SPT or positive sIgE results and clinical reactivity. ${ }^{94}$ Children who were sensitized to cockroach through environmental exposure had higher levels of IgE to shrimp, but they did not manifest clinical symptoms of shrimp allergy, suggesting that such extract-based SPT and IgE tests indicate only $\operatorname{IgE}$ sensitization but not necessarily clinical allergy. ${ }^{72,94}$ Another study also reported that all shellfish-allergic individuals with positive SPT or IgE test results passed the food challenge, ${ }^{95}$ which was consistent with previous reports. ${ }^{96}$

\section{Oral food challenge}

Oral food challenge is by far the only diagnostic test reflecting clinical food allergy, ${ }^{97}$ and positive food challenge usually correlates with strong SPT and IgE measurement results. ${ }^{93}$ Currently, there are three types of oral food challenges: open food challenge (OFC), single-blind placebo-controlled food challenge, and double-blind placebo-controlled food challenge (DBPCFC).

In OFC, food is given in its ordinary form such that both the observer and patient recognize the tested food. The use of OFC is largely due to its convenience in clinical settings. Furthermore, OFC is also conducted when the load of food is too large to be effectively masked in a blinded challenge, for confirming a negative DBPCFC result and for children under 3 years of age. ${ }^{98}$ The major flaw is obviously the high degree of bias by either the observer or the patient.

In single-blind placebo-controlled food challenge, only the patients are unaware of the kind of food administered, whereas the observer and patient are both unaware of the 
tested food in DBPCFC. For both types of challenges, the taste and smell of the suspected causal food are blinded by masking with other foods that are tolerated by the subjects (ie, active provocation). Placebos made with the same preparation without the allergic food are also included in both types of challenges to evaluate the allergic symptoms (both subjective and objective). The active and placebo provocations will be performed on separate days and both are given to subjects from low to increasing doses until the first incidence of observed reaction. ${ }^{99}$ However, the methods for preparing blinded food for DBPCFC may vary among clinics, such as using chocolates for fish, and chocolate pudding or burgers for shrimp. ${ }^{99}$

While DBPCFC represents the gold standard in food allergy diagnosis, the major drawbacks limiting its applications in clinical practice are that it is time-consuming, laborintensive, and expensive. ${ }^{100}$ Oral food challenges also pose the risk of severe anaphylactic shock, ${ }^{101,102}$ and thus should be optimized for safety by cautiously considering the subjects' age, anticipated symptoms, SPT and sIgE levels, as well as the doses of the suspected allergic food used in the challenge and food contaminations before conducting a food challenge. ${ }^{103}$ It is also noteworthy that the allergenicity of seafood may be altered after thermoprocessing. ${ }^{104}$ For instance, some cooked shrimp and mollusk species extracts have higher allergenicity than raw preparations, ${ }^{105,106}$ whereas some other species were shown to induce higher IgE production when consumed raw. ${ }^{107}$

\section{Component-resolved diagnosis}

As discussed above, SPT and sIgE measurements only reflect IgE sensitization with suboptimal specificity, and do not predict the severity of allergic symptoms. ${ }^{100}$ The high cost and safety issues of DBPCFC have limited its use in clinical practice. CRD has been developed recently as an emerging strategy to overcome the shortcomings of these traditional methods. CRD aims at measuring IgE antibodies to individual allergenic components in the form of proteins or peptides ${ }^{108}$ to provide more details on the sensitizing profile of patients. ${ }^{109}$ The working principle of CRD is depicted in Figure 2.

The utility of CRD has been well demonstrated in peanut allergy. False-positive SPT and sIgE results are common in peanut-tolerant subjects ${ }^{110}$ that could be in part due to nonspecific IgE reactivity to carbohydrate determinants and/or pollen allergens in the preparation. ${ }^{111}$ It was found that subjects who failed food challenges inadvertently had higher sIgE to peanut allergens Ara h 1, 2, and 3, while positive sIgE to Ara h 8 was found in patients passing OFCs. Compared to peanut extracts that have a diagnostic specificity of only $17 \%$ and PPV of 0.67 , Ara $\mathrm{h} 2$ is a better diagnostic marker with a specificity of $92 \%$ and PPV of 0.94. By adding the level of Ara h 2-specific IgE as a second diagnostic step after detecting positive sIgE to peanut extract, 91.1\% Ara h 2-positive subjects failed a food challenge while $78.6 \%$ of Ara h 2-negative subjects passed. This suggests that Ara $\mathrm{h} 2$ is a more specific marker than peanut extract for identifying challenge-proven peanut allergy, and that sIgE level to Ara $\mathrm{h} 2$ can be an indicator to reduce the need for OFC. ${ }^{112}$

For fish and shellfish allergies, single-plex CRD can be performed on the ImmunoCAP system (Phadia/Thermo Fisher Scientific, Uppsala, Sweden) against fish parvalbumins rCyp c 1 and $\mathrm{rGad} \mathrm{c}$ 1, as well as shrimp TM rPen a $1 .{ }^{113-115}$ ImmunoCAP allows quantification of sIgE level at standard unit (ie, kUA/L) but requires a larger amount of sera for analysis as each allergen

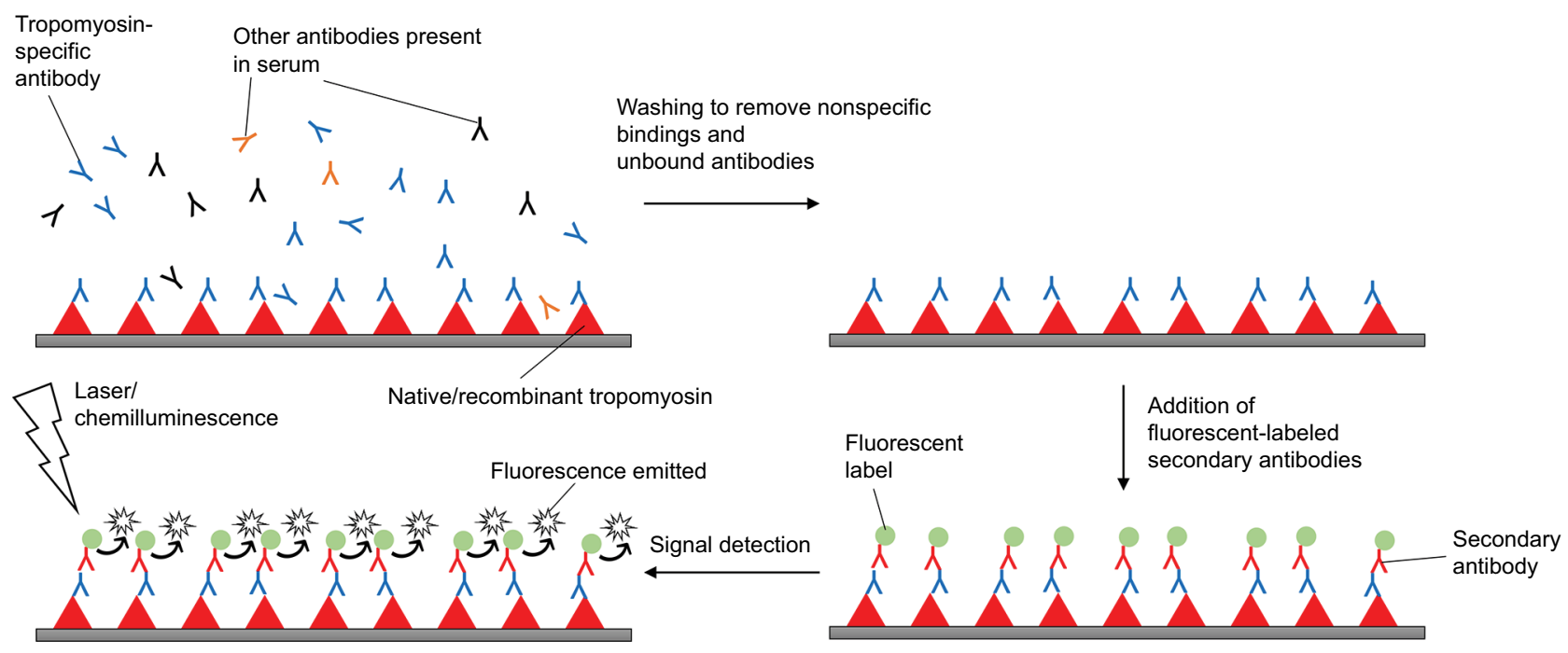

Figure 2 Working principle of component-resolved diagnosis, using shrimp tropomyosin as an example. 
component is tested individually. This might limit its application among pediatric subjects. Microarray-based ImmunoCAP ISAC system (Immuno-Solid Phase Allergen Chip; Phadia/ Thermo Fisher Scientific) is also available, by which the allergen panel covers 112 inhalation and common food allergens that include cod (rGad c 1) and shrimp (nPen m 1, nPen $\mathrm{m} 2$ and $\mathrm{rPen} \mathrm{m}$ 4) allergens. ${ }^{16,117}$ Although the results between the ImmunoCAP and ISAC platforms are closely correlated, the sensitivity of ISAC is lower than that of ImmunoCAP. ${ }^{118}$

Studies on the diagnostic utility of CRD in fish and shellfish allergies are lacking. Currently, in vitro assays of serologic IgE reactivity to recombinant fish parvalbumin are often used to assess for clinical cross-reactivity in fish allergy. ${ }^{23,119}$ A few studies, however, revealed that there was IgE binding to other allergens other than parvalbumin in patients. Monosensitivity to some fish species including swordfish and cod was observed in some patients. For example, Kelso et al found allergy specific to swordfish and not to the other nine commercial fish extracts tested. ${ }^{120}$ Kuehn et al also demonstrated the correlation of fish enolases- and aldolases-specific IgE with clinical sensitivity in three codsensitized but parvalbumin-nonreactive patients. ${ }^{121}$ Inclusion of the minor fish allergens such as enolases, aldolases, and perhaps gelatin into the testing panel will likely enhance the resolution of fish allergy diagnosis.

On the other hand, for shellfish allergy, it was reported that $\mathrm{IgE}$ reactivity to shrimp TM rPen a 1 was detected in $98 \%$ of shrimp-allergic patients, ${ }^{122}$ and shrimp TM-specific IgE level can better predict clinical reactivity than SPT and IgE to shrimp extract at a specificity of $92.8 \%$ compared to $75 \%$ and $64.2 \%$ only, respectively. ${ }^{123}$ A more comprehensive study by Pascal et al included the proteins and peptides of TM (Lit v 1), AK (Lit v 2), MLC (Lit v 3), SCP isoform alpha (Lit v 4), hemocyanin (HM), fatty-acid-binding protein, SCP isoform beta, and troponin $\mathrm{C}$ to study the utility of CRD for shrimp allergy diagnosis. ${ }^{68}$ The sensitization profile suggested that apart from TM, which accounts for the majority of allergic symptoms after shellfish ingestion, SCP was also highly associated with allergic manifestations and MLC was a predictive marker of positive oral food challenge. AK and hemocyanin were, on the other hand, markers of cross-reactivity with a recognition frequency higher than $60 \%$ in house dust mite- and/or cockroach-allergic patients. Furthermore, the study by Asero et al reported that shrimpallergic subjects with strong Pen $\mathrm{m} 1$ hypersensitivity showed positive SPT with extracts depleted of TM and they frequently reacted to other minor allergens such as Pen $\mathrm{m} 2$ and Pen $\mathrm{m}$ 4 on ISAC, as well as other high-molecular-weight shrimp allergens. ${ }^{81}$ These two independent studies, thus, highlight the uncomprehensiveness of the current shellfish allergen panel, and perhaps fish allergy as well, which intelligibly challenge our development of CRD.

\section{Future perspectives}

Advances in the molecular and physiochemical characterization of shellfish and fish allergens have facilitated the development of CRD that can lead to more precise diagnoses and better clinical management of these allergies. However, there are still significant areas that need to be refined regarding the diagnosis of shellfish and fish allergies:

1. Although many shellfish and fish allergens are identified at the molecular level to date, few of these recombinant proteins are employed in diagnostic assays. Thus far, TM is the only allergen identified across different edible crustacean and mollusk species. The report by Asero et al, however, pointed out that TM may not be the only allergen for shellfish allergy diagnosis and emphasizes the values of other clinically important shellfish allergens. Identifying and characterizing seafood allergens, especially species-specific allergens, may advance the resolution of fish and shellfish allergy diagnosis. ${ }^{81}$

2. Although CRD is an emerging method that could potentially reduce the need for oral food challenge and contribute to tailored treatment plans based on patients' sensitization profiles, it is yet to be considered as a routine diagnostic method. ${ }^{97}$ The diagnostic utility of CRD for fish and shellfish allergies is also yet to be thoroughly investigated.

3. Other emerging diagnostic tests are also worth investigating, including epitope binding, T-cell response, basophil activation assays, and atopy patch test. It is worth noting that sIgE measurements to extracts or allergen components indeed reflect the affinity between IgE and the allergens but not necessarily their ability to trigger subsequent degranulation in the effector cells. This issue could be addressed by using basophil activation test, which has been suggested to differentiate between subjects allergic to or tolerant to peanut, milk, and egg. ${ }^{124-126}$

\section{Conclusion}

With the increasing worldwide prevalence of seafood allergy, the precise diagnosis of this disorder is crucial for appropriate management strategies and unnecessary dietary avoidance. The current diagnostic methods in clinical practice for food allergy are often held back by the suboptimal 
specificity and safety and economic issues, especially for oral food challenges and allergen cross-reactivity. Incorporating CRD into the diagnostic workup might increase the resolution to the severity of allergic symptoms, resolve clinical cross-reactivity, and circumvent the need for oral food challenge. However, we should always appreciate that precise diagnosis should be achieved through a stepwise approach incorporating different tests to complement both sensitivity and specificity. We note that diagnosis of fish and shellfish allergy indeed becomes complicated by the extensive cross-reactivity among fish allergens and between allergens in edible shellfish and other arthropods. Largescale studies evaluating the diagnostic accuracy and utility of the conventional tests and other emerging strategies for these allergies are also lacking. Advances in validation studies, together with the development of next-generation diagnostic strategies, are needed to improve the specificity of diagnostic workups for food allergies.

\section{Acknowledgment}

Christine YY Wai is currently funded as an AXA Postdoctoral Fellow (AXA Research Fund).

\section{Disclosure}

The authors report no conflicts of interest in this work.

\section{References}

1. Hill DA, Grundmeier RW, Ram G, Spergel JM. The epidemiologic characteristics of healthcare provider-diagnosed eczema, asthma, allergic rhinitis, and food allergy in children: a retrospective cohort study. BMC Pediatr. 2016;16(1):133.

2. Taylor SL, Hefle SL, Bindslev-Jensen C, et al. Factors affecting the determination of threshold doses for allergenic foods: how much is too much? J Allergy Clin Immunol. 2002;109(1):24-30.

3. Untersmayr E, Vestergaard H, Malling H-J, et al. Incomplete digestion of codfish represents a risk factor for anaphylaxis in patients with allergy. J Allergy Clin Immunol. 2007;119(3):711-717.

4. Gupta RS, Springston EE, Warrier MR, et al. The prevalence, severity, and distribution of childhood food allergy in the United States. Pediatrics. 2011;128(1):e9-e17.

5. Rona RJ, Keil T, Summers C, et al. The prevalence of food allergy: a meta-analysis. J Allergy Clin Immunol. 2007;120(3):638-646.

6. Sicherer SH, Muñoz-Furlong A, Sampson HA. Prevalence of seafood allergy in the United States determined by a random telephone survey. J Allergy Clin Immunol. 2004;114(1):159-165.

7. Connett GJ, Gerez I, Cabrera-Morales EA, et al. A population-based study of fish allergy in the Philippines, Singapore and Thailand. Int Arch Allergy Immunol. 2012;159(4):384-390.

8. Chiang WC, Kidon MI, Liew WK, Goh A, Tang JPL, Chay OM. The changing face of food hypersensitivity in an Asian community. Clin Exp Allergy. 2007;37(7):1055-1061.

9. Smit DV, Cameron PA, Rainer TH. Anaphylaxis presentations to an emergency department in Hong Kong: incidence and predictors of biphasic reactions. J Emerg Med. 2005;28(4):381-388.

10. Hsin YC, Hsin YC, Huang JL, Yeh KW. Clinical features of adult and pediatric anaphylaxis in Taiwan. Asian Pacific J Allergy Immunol. 2011;29(4):307-312.
11. KatzY, Goldberg MR, Rajuan N, Cohen A, Leshno M. The prevalence and natural course of food protein-induced enterocolitis syndrome to cow's milk: a large-scale, prospective population-based study. J Allergy Clin Immunol. 2011;127(3):647-653.

12. Food and Agriculture Organization of the United Nations. FAO Fisheries and Aquaculture Department summary tables of fishery statistics. Available from: http://www.fao.org/fishery/docs/STAT/summary/ default.htm. Accessed January 31, 2018.

13. Aas K, Elsayed SM. Characterization of a major allergen (cod). Effect of enzymic hydrolysis on the allergenic activity. $J$ Allergy. 1969;44(6):333-343.

14. Bugajska-Schretter A, Elfman L, Fuchs T, et al. Parvalbumin, a cross-reactive fish allergen, contains IgE-binding epitopes sensitive to periodate treatment and $\mathrm{Ca} 2+$ depletion. J Allergy Clin Immunol. 1998;101(1):67-74.

15. Griesmeier U, Bublin M, Radauer C, et al. Physicochemical properties and thermal stability of Lep w 1, the major allergen of whiff. Mol Nutr Food Res. 2009;54(6):861-869.

16. Elsayed S, Aas K. Characterization of a major allergen (cod). Observations on effect of denaturation on the allergenic activity. J Allergy. 1971;47(5):283-291.

17. Kobayashi A, Tanaka H, Hamada Y, Ishizaki S, Nagashima Y, Shiomi $\mathrm{K}$. Comparison of allergenicity and allergens between fish white and dark muscles. Allergy. 2006;61(3):357-363.

18. Goodman M, Pechére J-F. The evolution of muscular parvalbumins investigated by the maximum parsimony method. J Mol Evol. 1977;9(2): 131-158.

19. Goodman M, Pechére J-F, Haiech J, Demaille JG. Evolutionary diversification of structure and function in the family of intracellular calcium-binding proteins. J Mol Evol. 1979;13(4):331-352.

20. Radauer C, Bublin M, Wagner S, Mari A, Breiteneder H. Allergens are distributed into few protein families and possess a restricted number of biochemical functions. JAllergy Clin Immunol. 2008;121(4):847-852.

21. Kuehn A, Swoboda I, Arumugam K, Hilger C, Hentges Franãßois, Hentges F. Fish allergens at a glance: variable allergenicity of parvalbumins, the major fish allergens. Front Immunol. 2014;5:179.

22. Liu R, Holck AL, Yang E, Liu C, Xue W. Tropomyosin from tilapia (Oreochromis mossambicus) as an allergen. Clin Exp Allergy. 2013;43(3): 365-377.

23. Kuehn A, Hilger C, Lehners-Weber C, et al. Identification of enolases and aldolases as important fish allergens in cod, salmon and tuna: component resolved diagnosis using parvalbumin and the new allergens. Clin Exp Allergy. 2013;43(7):811-822.

24. Tomm JM, van Do T, Jende C, Simon JC, Treudler R, von Bergen $\mathrm{M}$, Averbeck M. Identification of new potential allergens from Nile perch (Lates niloticus) and cod (Gadus morhua). J Investig Allergol Clin Immunol. 2013;23(3):159-167.

25. Sakaguchi M, Toda M, Ebihara T, et al. IgE antibody to fish gelatin (type I collagen) in patients with fish allergy. J Allergy Clin Immunol. 2000;106(3):579-584.

26. Hamada Y, Nagashima Y, Shiomi K. Identification of collagen as a new fish allergen. Biosci Biotechnol Biochem. 2001;65(2):285-291.

27. Hansen TK, Poulsen LK, Stahl Skov P, et al. A randomized, doubleblinded, placebo-controlled oral challenge study to evaluate the allergenicity of commercial, food-grade fish gelatin. Food Chem Toxicol. 2004;42(12):2037-2044.

28. das Dores S, Chopin C, Romano A, et al. IgE-binding and cross-reactivity of a new $41 \mathrm{kDa}$ allergen of codfish. Allergy. 2002;57(s72):84-87.

29. Hamada Y, Nagashima Y, Shiomi K, et al. Reactivity of IgE in fish-allergic patients to fish muscle collagen. Allergol Int. 2003;52(3):139-147.

30. Nakamura R, Satoh R, Nakajima Y, et al. Comparative study of GHtransgenic and non-transgenic amago salmon (Oncorhynchus masou ishikawae) allergenicity and proteomic analysis of amago salmon allergens. Regul Toxicol Pharmacol. 2009;55(3):300-308.

31. Rosmilah M, Shahnaz M, Meinir J, Masita A, Noormalin A, Jamaluddin M. Identification of parvalbumin and two new thermolabile major allergens of Thunnus tonggol using a proteomics approach. Int Arch Allergy Immunol. 2013;162(4):299-309. 
32. de Martino M, Novembre E, Galli L, et al. Allergy to different fish species in cod-allergic children: in vivo and in vitro studies. J Allergy Clin Immunol. 1990;86(6):909-914.

33. Sten E, Hansen TK, Stahl Skov P, et al. Cross-reactivity to eel, eelpout and ocean pout in codfish-allergic patients. Allergy. 2004;59(11):1173-1180.

34. Vando T, Elsayed S, Florvaag E, Hordvik I, Endresen C. Allergy to fish parvalbumins: studies on the cross-reactivity of allergens from 9 commonly consumed fish. JAllergy Clin Immunol. 2005;116(6):1314-1320.

35. Bernhisel-Broadbent J, Scanlon SM, Sampson HA. Fish hypersensitivity. I. In vitro and oral challenge results in fish-allergic patients. $J$ Allergy Clin Immunol. 1992;89(3):730-737.

36. Hansen TK, Bindslev-Jensen C, Skov PS, Poulsen LK. Codfish allergy in adults: IgE cross-reactivity among fish species. Ann Allergy Asthma Immunol. 1997;78(2):187-194.

37. D1-C L, Neo KH, Fc Y, et al. Parvalbumin - the major tropical fish allergen. Pediatr Allergy Immunol. 2008;19(5):399-407.

38. Helbling A, Haydel R, Mccants ML, Musmand JJ, El-Dahr J, Lehrer SB. Fish allergy: is cross-reactivity among fish species relevant? Double-blind placebo-controlled food challenge studies of fish allergic adults. Ann Allergy Asthma Immunol. 1999;83(6):517-523.

39. Hilger $\mathrm{C}$, Thill $\mathrm{L}$, Grigioni $\mathrm{F}$, et al. IgE antibodies of fish allergic patients cross-react with frog parvalbumin. Allergy. 2004;59(6):653-660

40. Kuehn A, Codreanu-Morel F, Lehners-Weber C, et al. Cross-reactivity to fish and chicken meat - a new clinical syndrome. Allergy. 2016;71(12) $1772-1781$

41. Gámez C, Zafra MP, Boquete M, et al. New shrimp IgE-binding proteins involved in mite-seafood cross-reactivity. Mol Nutr Food Res. 2014;58(9):1915-1925.

42. Pedrosa M, Boyano-Martínez T, García-Ara C, Quirce S. Shellfish allergy: a comprehensive review. Clin Rev Allergy Immunol. 2015;49(2):203-216.

43. Shanti KN, Martin BM, Nagpal S, Metcalfe DD, Rao PV. Identification of tropomyosin as the major shrimp allergen and characterization of its IgE-binding epitopes. J Immunol. 1993;151(10):5354-5363.

44. Yong Jeong K, Hong C-S, Yong T-S. Allergenic tropomyosins and their cross-reactivities. Protein Pept Lett. 2006;13(8):835-845.

45. Usui M, Harada A, Ishimaru T, et al. Contribution of structural reversibility to the heat stability of the tropomyosin shrimp allergen. Biosci Biotechnol Biochem. 2013;77(5):948-953.

46. Usui M, Harada A, Yasumoto S, et al. Relationship between the risk for a shrimp allergy and freshness or cooking. Biosci Biotechnol Biochem. 2015;79(10):1698-1701

47. CjY, Lin YF, Chiang BL, Chow LP. Proteomics and immunological analysis of a novel shrimp allergen, Pen m 2. J Immunol. 2003;170(1):445-453.

48. H1 Y, Ruan WW, Cao MJ, Cai QF, Shen HW, Liu GM. Identification of physicochemical properties of Scylla paramamosain allergen, arginin kinase. J Sci Food Agric. 2013;93(2):245-253.

49. Rosmilah M, Shahnaz M, Zailatul HM, Noormalin A, Normilah I. Identification of tropomyosin and arginine kinase as major allergens of Portunus pelagicus (blue swimming crab). Trop Biomed. 2012;29(3):467-478.

50. Ayuso R, Grishina G, Bardina L, et al. Myosin light chain is a novel shrimp allergen, Lit v 3. JAllergy Clin Immunol. 2008;122(4):795-802.

51. Zhang Y-X, Chen H-L, Maleki SJ, Cao MJ, Zhang LJ, Su WJ, Liu GM. Purification, characterization, and analysis of the allergenic properties of myosin light chain in Procambarus clarkii. J Agric Food Chem. 2015;63(27):6271-6282.

52. Ayuso R, Grishina G, Ibáñez MD, et al. Sarcoplasmic calcium-binding protein is an EF-hand-type protein identified as a new shrimp allergen. J Allergy Clin Immunol. 2009;124(1):114-120.

53. Mita H, Koketsu A, Ishizaki S, Shiomi K. Molecular cloning and functional expression of allergenic sarcoplasmic calcium-binding proteins from Penaeus shrimps. J Sci Food Agric. 2013;93(7):1737-1742.

54. Abdel Rahman AM, Kamath SD, Lopata AL, Robinson JJ, Helleur RJ. Biomolecular characterization of allergenic proteins in snow crab (Chionoecetes opilio) and de novo sequencing of the second allergen arginine kinase using tandem mass spectrometry. $J$ Proteomics. 2011;74(2):231-241
55. Bauermeister K, Wangorsch A, Garoffo LP, et al. Generation of a comprehensive panel of crustacean allergens from the North Sea Shrimp Crangon crangon. Mol Immunol. 2011;48(15-16):1983-1992.

56. Piboonpocanun S, Jirapongsananuruk O, Tipayanon T, Boonchoo S, Goodman RE. Identification of hemocyanin as a novel non-crossreactive allergen from the giant freshwater shrimp Macrobrachium rosenbergii. Mol Nutr Food Res. 2011;55(10):1492-1498.

57. Abdel Rahman AM, Kamath SD, Gagné S, Lopata AL, Helleur R. Comprehensive proteomics approach in characterizing and quantifying allergenic proteins from Northern shrimp: toward better occupational asthma prevention. J Proteome Res. 2013;12(2):647-656.

58. Suzuki M, Kobayashi Y, Hiraki Y, Nakata H, Shiomi K. Paramyosin of the disc abalone Haliotis discus discus: identification as a new allergen and cross-reactivity with tropomyosin. Food Chem. 2011;124(3): 921-926.

59. Chu KH, Wong SH, Leung PSC. Tropomyosin is the major mollusk allergen: reverse transcriptase polymerase chain reaction, expression and IgE reactivity. Mar Biotechnol. 2000;2(5):499-509.

60. Leung PSC, Chen Y-Chen, Gershwin ME, Wong SH, Kwan HS, Chu KH. Identification and molecular characterization of Charybdis feriatus tropomyosin, the major crab allergen. JAllergy Clin Immunol. 1998;102(5):847-852.

61. Faber MA, Pascal M, El Kharbouchi O, et al. Shellfish allergens: tropomyosin and beyond. Allergy. 2017;72(6):842-848.

62. Motoyama K, Ishizaki S, Nagashima Y, Shiomi K. Cephalopod tropomyosins: identification as major allergens and molecular cloning. Food Chem Toxicol. 2006;44(12):1997-2002.

63. Jirapongsananuruk O, Sripramong C, Pacharn P, et al. Specific allergy to Penaeus monodon (seawater shrimp) or Macrobrachium rosenbergii (freshwater shrimp) in shrimp-allergic children. Clin Exp Allergy. 2008;38(6):1038-1047.

64. Leung PSC, Chow WK, Duffey S, Kwan HS, Gershwin ME, Chu $\mathrm{KH}$. IgE reactivity against a cross-reactive allergen in crustacea and mollusca: evidence for tropomyosin as the common allergen. JAllergy Clin Immunol. 1996;98(5):954-961.

65. Ayuso R, Reese G, Leong-Kee S, Plante M, Lehrer SB. Molecular basis of arthropod cross-reactivity: IgE-binding cross-reactive epitopes of shrimp, house dust mite and cockroach tropomyosins. Int Arch Allergy Immunol. 2002;129(1):38-48.

66. Yang Z, Zhao J, Wei N, et al. Cockroach is a major cross-reactive allergen source in shrimp-sensitized rural children in southern China. Allergy. 2018;73(3):585-592.

67. Fernandes J, Reshef A, Patton L, Ayuso R, Reese G, Lehrer SB. Immunoglobulin $\mathrm{E}$ antibody reactivity to the major shrimp allergen, tropomyosin, in unexposed Orthodox Jews. Clin Exp Allergy. 2003;33(7):956-961.

68. Pascal M, Grishina G, Yang AC, et al. Molecular diagnosis of shrimp allergy: efficiency of several allergens to predict clinical reactivity. $J$ Allergy Clin Immunol. 2015;3(4):521-529.

69. Peixoto S, Monteiro T, Carvalho M, et al. Vertebrate tropomyosin as an allergen. J Investig Allergol Clin Immunol. 2018;28(1):51-53.

70. González-Fernández J, Veleiro B, Daschner A, Cuéllar C. Are fish tropomyosins allergens? Ann Allergy, Asthma Immunol. 2016;116(1):74-76.

71. González-Fernández J, Daschner A, Cuéllar C. Allergenicity of vertebrate tropomyosins: challenging an immunological dogma. Allergol Immunopathol. 2017;45(3):297-304.

72. Sampson HA, Allergy F. Part 2: diagnosis and management. JAllergy Clin Immunol. 1999;103(6):981-989.

73. Abrams EM, Sicherer SH. Diagnosis and management of food allergy. Can Med Assoc J. 2016;188(15):1087-1093.

74. Liu X, Zhang S, Tsai H-J, et al. Genetic and environmental contributions to allergen sensitization in a Chinese twin study. Clin Exp Allergy. 2009;39(7):991-998.

75. Tsabouri S, Triga M, Makris M, Kalogeromitros D, Church MK, Priftis KN. Fish and shellfish allergy in children: review of a persistent food allergy. Pediatr Allergy Immunol. 2012;23(7):608-615.

76. Heinzerling L, Mari A, Bergmann K-C, et al. The skin prick test European standards. Clin Transl Allergy. 2013;3(1):3. 
77. Pariyaprasert W, Piboonpocanun S, Jirapongsananuruk O, Visitsunthorn N. Stability and potency of raw and boiled shrimp extracts for skin prick test. Asian Pacific J Allergy Immunol. 2015;33(2): 136-142.

78. Bernstein DI, Wanner M, Borish L, Liss GM, Immunotherapy Committee, American Academy of Allergy, Asthma and Immunology. Twelve-year survey of fatal reactions to allergen injections and skin testing: 1990-2001. JAllergy Clin Immunol. 2004;113(6):1129-1136.

79. Novembre E, Bernardini R, Bertini G, Massai G, Vierucci A. Skinprick-test-induced anaphylaxis. Allergy. 1995;50(6):511-513.

80. Kianifar HR, Pourreza A, Jabbari Azad F, Yousefzadeh H, Masomi F. Sensitivity comparison of the skin prick test and serum and fecal radio allergosorbent test (RAST) in diagnosis of food allergy in children. Rep Biochem Mol Biol. 2016;4(2):98-103.

81. Asero R, Scala E, Villalta D, et al. Shrimp allergy: analysis of commercially available extracts for in vivo diagnosis. $J$ Investig Allergol Clin Immunol. 2017;27(3):175-182.

82. Kuehn A, Scheuermann T, Hilger C, Hentges F. Important variations in parvalbumin content in common fish species: a factor possibly contributing to variable allergenicity. Int Arch Allergy Immunol. 2010;153(4):359-366.

83. Rancé F, Juchet A, Brémont F, Dutau G. Correlations between skin prick tests using commercial extracts and fresh foods, specific IgE, and food challenges. Allergy Eur J Allergy Clin Immunol. 1997;52(10): 1031-1035.

84. Zawodniak A, Kupczyk M, Górski P, Kuna P. Comparison of standard and modified SPT method. Allergy Eur J Allergy Clin Immunol. 2003;58(3):257-259.

85. Morell F, Codina R, Rodrigo MJ. Increased positivity of skin test and allergenic stability of glycerinated soybean hull extracts. Clin Exp Allergy. 1999;29(3):388-393.

86. Eigenmann PA, Sampson HA. Interpreting skin prick tests in the evaluation of food allergy in children. Pediatr Allergy Immunol. 1998;9(4):186-191.

87. Myrset HR, Barletta B, di Felice G, Egaas E, Dooper MMBW. Structural and immunological characterization of recombinant Pan b 1, a major allergen of Northern shrimp, Pandalus borealis. Int Arch Allergy Immunol. 2013;160(3):221-232.

88. Peters R, Gurrin L, Dharmage S, Koplin J, Allen K. The natural history of IgE-mediated food allergy: can skin prick tests and serum-specific IgE predict the resolution of food allergy? Int J Environ Res Public Health. 2013;10(10):5039-5061.

89. Cox L. Overview of serological-specific IgE antibody testing in children. Curr Allergy Asthma Rep. 2011;11(6):447-453.

90. Celik-Bilgili S, Mehl A, Verstege A, et al. The predictive value of specific immunoglobulin E levels in serum for the outcome of oral food challenges. Clin Exp Allergy. 2005;35(3):268-273.

91. Mekaroonkamol J, Chatchatee P, Ngamphaiboon J, Lertchanaruengrith P, Suratannon N. Predicting shrimp allergy using skin prick test, specific IgE to shrimp and Rpen a1 in area with high prevalence of house dust mite sensitization. J Allergy Clin Immunol. 2015;135(2):AB248.

92. Sampson HA. Utility of food-specific IgE concentrations in predicting symptomatic food allergy. J Allergy Clin Immunol. 2001;107(5): 891-896.

93. Perry TT, Matsui EC, Kay Conover-Walker M, Wood RA. The relationship of allergen-specific IgE levels and oral food challenge outcome. J Allergy Clin Immunol. 2004;114(1):144-149.

94. Wang J, Calatroni A, Visness CM, Sampson HA. Correlation of specific IgE to shrimp with cockroach and dust mite exposure and sensitization in an inner-city population. J Allergy Clin Immunol. 2011;128(4):834-837.

95. Fleischer DM, Bock SA, Spears GC, et al. Oral food challenges in children with a diagnosis of food allergy. J Pediatr. 2011;158(4):578-583.

96. Sampson HA, Mccaskill CC. Food hypersensitivity and atopic dermatitis: evaluation of 113 patients. J Pediatr. 1985;107(5):669-675.

97. Boyce JA, Assa'ad A, Burks AW, et al. Guidelines for the diagnosis and management of food allergy in the United States: summary of the NIAID-sponsored expert panel report. J Allergy Clin Immunol. 2010;126(6):1105-1118.
98. Nowak-Węgrzyn A, Assa'ad AH, Bahna SL, Bock SA, Sicherer SH, Teuber SS. Work Group report: oral food challenge testing. J Allergy Clin Immunol. 2009;123(6Suppl):S365-S383.

99. Fernández-Rivas M, Barreales L, Mackie AR, et al. The EuroPrevall outpatient clinic study on food allergy: background and methodology. Allergy Eur J Allergy Clin Immunol. 2015;70(5):576-584.

100. Kim JF, Nwaru BI, Mccleary N, Stoddart A, Sheikh A. Investigating the accuracy, risk impact, and cost-effectiveness of component-resolved diagnostic test for food allergy: a systematic review protocol. NPJ Prim Care Respir Med. 2017;27(1):1-2.

101. Cianferoni A, Khullar K, Saltzman R, et al. Oral food challenge to wheat: a near-fatal anaphylaxis and review of 93 food challenges in children. World Allergy Organ J. 2013;6(1):14.

102. Sampson HA, Mendelson L, Rosen JP. Fatal and near-fatal anaphylactic reactions to food in children and adolescents. $N$ Engl J Med. 1992;327(6):380-384.

103. Bahna SL. Food challenge procedure: optimal choices for clinical practice. Allergy Asthma Proc. 2007;28(6):640-646.

104. Thomas K, Herouet-Guicheney C, Ladics G, et al. Evaluating the effect of food processing on the potential human allergenicity of novel proteins: international workshop report. Food Chem Toxicol. 2007;45(7):1116-1122.

105. Carnés J, Ferrer Ángel, Huertas Ángel J, Andreu C, Larramendi CH, Fernández-Caldas E. The use of raw or boiled crustacean extracts for the diagnosis of seafood allergic individuals. Ann Allergy Asthma Immunol. 2007;98(4):349-354.

106. Lopata AL, Zinn C, Potter PC. Characteristics of hypersensitivity reactions and identification of a unique $49 \mathrm{kd}$ IgE-binding protein (Hal-m1) in abalone (Haliotis midae). J Allergy Clin Immunol. 1997;100(5): 642-648.

107. Yadzir ZH, Misnan R, Bakhtiar F, Abdullah N, Murad S. Tropomyosin, the major tropical oyster Crassostrea belcheri allergen and effect of cooking on its allergenicity. Allergy Asthma Clin Immunol. 2015;11(1):30.

108. Wolthers OD. Component-resolved diagnosis in pediatrics. ISRN Pediatr. 2012;2012:806920.

109. Incorvaia C, Rapetti A, Aliani M, et al. Food allergy as defined by component resolved diagnosis. Recent Pat Inflamm Allergy Drug Discov. 2014;8(1):59-73.

110. Beyer K, Ellman-Grunther L, Järvinen KM, Wood RA, Hourihane J, Sampson HA. Measurement of peptide-specific IgE as an additional tool in identifying patients with clinical reactivity to peanuts. JAllergy Clin Immunol. 2003;112(1):202-207.

111. Nicolaou N, Poorafshar M, Murray C, et al. Allergy or tolerance in children sensitized to peanut: prevalence and differentiation using component-resolved diagnostics. JAllergy Clin Immunol. 2010;125(1): 191-197.

112. Wang J, Sampson HA. Food allergy. J Clin Invest. 2011;121(3):827-835.

113. Thermo Fisher Scientific. Allergen component: rCyp c 1 carp. Available from: http:/www.phadia.com/en/Products/Allergy-testing-products/ ImmunoCAP-Allergen-Information/Food-of-Animal-Origin/AllergenComponents/rCyp-c-1-Carp/. Accessed May 22, 2018.

114. Thermo Fisher Scientific. Allergen component: rGad c 1, cod. Available from: http://www.phadia.com/en/Products/Allergy-testing-products/ ImmunoCAP-Allergen-Information/Food-of-Animal-Origin/AllergenComponents/rGad-c-1-Cod/. Accessed May 22, 2018.

115. Thermo Fisher Scientific. Allergen component: rPen a 1 tropomyosin, shrimp. Available from: http://www.phadia.com/en/Products/Allergytesting-products/ImmunoCAP-Allergen-Information/Food-of-AnimalOrigin/Allergen-Components/rPen-a-1-Tropomyosin-Shrimp/. Accessed May 22, 2018.

116. Lopata AL, Kleine-Tebbe J, Kamath SD. Allergens and molecular diagnostics of shellfish allergy: Part 22 of the Series Molecular Allergology. Allergo J Int. 2016;25(7):210-218.

117. Jakob T, Forstenlechner P, Matricardi P, Kleine-Tebbe J. Molecular allergy diagnostics using multiplex assays: methodological and practical considerations for use in research and clinical routine: Part 21 of the Series Molecular Allergology. Allergo J Int. 2015;24:320-332. 
118. Huss-Marp J, Gutermuth J, Schäffner I, et al. Comparison of molecular and extract-based allergy diagnostics with multiplex and singleplex analysis. Allergo J Int. 2015;24:46-53.

119. Swoboda I, Bugajska-Schretter A, Verdino P, et al. Recombinant carp parvalbumin, the major cross-reactive fish allergen: a tool for diagnosis and therapy of fish allergy. J Immunol. 2002;168(9):4576-4584.

120. Kelso JM, Jones RT, Yunginger JW. Monospecific allergy to swordfish. Ann Allergy Asthma Immunol. 1996;77(3):227-228.

121. Kuehn A, Fischer J, Hilger C, Sparla C, Biedermann T, Hentges F. Correlation of clinical monosensitivity to cod with specific IgE to enolase and aldolase. Ann Allergy Asthma Immunol. 2014;113(6):670-671.

122. Gámez C, Sánchez-García S, Ibáñez MD, et al. Tropomyosin IgEpositive results are a good predictor of shrimp allergy. Allergy Eur $J$ Allergy Clin Immunol. 2011;66(10):1375-1383.

123. Yang AC, Arruda LK, Santos AB, et al. Measurement of IgE antibodies to shrimp tropomyosin is superior to skin prick testing with commercial extract and measurement of $\operatorname{IgE}$ to shrimp for predicting clinically relevant allergic reactions after shrimp ingestion. J Allergy Clin Immunol. 2010;125(4):872-878.

124. Wanich N, Nowak-Wegrzyn A, Sampson HA, Shreffler WG. Allergenspecific basophil suppression associated with clinical tolerance in patients with milk allergy. J Allergy Clin Immunol. 2009;123(4):789-794.

125. Valdimarsson V, Sigurdardottir S, Skaftadottir I, Clausen M, Ludvigsson B. Basophil activation test for diagnosis of food allergy. J Allergy Clin Immunol. 2008;121(2):S250.

126. Ocmant A, Mulier S, Hanssens L, et al. Basophil activation tests for the diagnosis of food allergy in children. Clin Exp Allergy. 2009;39(8):1234-1245.

127. Swoboda I, Balic N, Klug C, et al. A general strategy for the generation of hypoallergenic molecules for the immunotherapy of fish allergy. $J$ Allergy Clin Immunol. 2013;132(4):979-981.

128. Bugajska-Schretter A, Grote M, Vangelista L, et al. Purification, biochemical, and immunological characterisation of a major food allergen: different immunoglobulin E recognition of the apo- and calcium-bound forms of carp parvalbumin. Gut. 2000;46(5):661-669.

129. van do T, Hordvik I, Endresen C, Elsayed S. The major allergen (parvalbumin) of codfish is encoded by at least two isotypic genes: cDNA cloning, expression and antibody binding of the recombinant allergens. Mol Immunol. 2003;39(10):595-602.

130. Sharp MF, Kamath SD, Koeberl M, et al. Differential IgE binding to isoallergens from Asian seabass (Lates calcarifer) in children and adults. Mol Immunol. 2014;62(1):77-85.

131. Mäkinen-Kiljunen S, Kiistala R, Varjonen E. Severe reactions from roe without concomitant fish allergy. Ann Allergy Asthma Immunol. 2003;91(4):413-416.

132. Ruethers T, Raith M, Sharp MF, et al. Characterization of Ras k 1 a novel major allergen in Indian mackerel and identification of parvalbumin as the major fish allergen in 33 Asia-Pacific fish species. Clin Exp Allergy. 2018;48(4):452-463.

133. Lindstrøm CD, van Dô T, Hordvik I, Endresen C, Elsayed S. Cloning of two distinct cDNAs encoding parvalbumin, the major allergen of Atlantic salmon (Salmo salar). Scand J Immunol. 1996;44(4): 335-344.

134. Beale JE, Jeebhay MF, Lopata AL. Characterisation of purified parvalbumin from five fish species and nucleotide sequencing of this major allergen from Pacific pilchard, Sardinops sagax. Mol Immunol. 2009;46(15):2985-2993.

135. Gajewski KG, Hsieh YH. Monoclonal antibody specific to a major fish allergen: parvalbumin. J Food Prot. 2009;72(4):818-825.

136. Griesmeier U, Vázquez-Cortés S, Bublin M, et al. Expression levels of parvalbumins determine allergenicity of fish species. Allergy Eur J Allergy Clin Immunol. 2010;65(2):191-198.

137. Kondo Y, Kakami M, Koyama H, et al. IgE cross-reactivity between fish roe (Salmon, Herring and Pollock) and chicken egg in patients anaphylactic to Salmon Roe. Allergol Int. 2005;54(2):317-323.

138. Leung PS, Chen YC, Mykles DL, Chow WK, Li CP, Chu KH. Molecular identification of the lobster muscle protein tropomyosin as a seafood allergen. Mol Mar Biol Biotechnol. 1998;7(1):12-20.
139. Liu GM, Cheng H, Nesbit JB, Su WJ, Cao MJ, Maleki SJ. Effects of boiling on the IgE-binding properties of tropomyosin of shrimp (Litopenaeus vannamei). J Food Sci. 2010;75(1):T1-T5.

140. Kumjim S, Jirapongsananuruk O, Piboonpocanun S. Cloning and characterization of recombinant tropomyosin of giant freshwater shrimp $M$. rosenbergii to determine major allergens causing allergic reactions among shrimp-allergic children. Asian Pac J Allergy Immunol. 2016;34(3):229-235.

141. Koeberl M, Kamath SD, Saptarshi SR, et al. Auto-induction for high yield expression of recombinant novel isoallergen tropomyosin from King prawn (Melicertus latisulcatus) for improved diagnostics and immunotherapeutics. J Immunol Methods. 2014;415:6-16.

142. Leung PS, Chu KH, Chow WK, et al. Cloning, expression, and primary structure of Metapenaeus ensis tropomyosin, the major heat-stable shrimp allergen. J Allergy Clin Immunol. 1994;94(5):882-890.

143. Daul CB, Slattery M, Reese G, Lehrer SB. Identification of the major brown shrimp (Penaeus aztecus) allergen as the muscle protein tropomyosin. Int Arch Allergy Immunol. 1994;105(1):49-55.

144. Abdel Rahman AM, Rahman AM, Kamath S, Lopata AL, Helleur RJ. Analysis of the allergenic proteins in black tiger prawn (Penaeus monodon) and characterization of the major allergen tropomyosin using mass spectrometry. Rapid Commun Mass Spectrom. 2010;24(16):2462-2470.

145. García-Orozco KD, Aispuro-Hernández E, Yepiz-Plascencia G, Calderón-de-La-Barca AM, Sotelo-Mundo RR. Molecular characterization of arginine kinase, an allergen from the shrimp Litopenaeus vannamei. Int Arch Allergy Immunol. 2007;144(1):23-28.

146. Mykles DL. Heterogeneity of myofibrillar proteins in lobster fast and slow muscles: variants of troponin, paramyosin, and myosin light chains comprise four distinct protein assemblages. J Exp Zool. 1985;234(1):23-32.

147. Shiomi K, Sato Y, Hamamoto S, Mita H, Shimakura K. Sarcoplasmic calcium-binding protein: identification as a new allergen of the black tiger shrimp Penaeus monodon. Int Arch Allergy Immunol. 2008;146(2):91-98.

148. Kobayashi T, Takagi T, Konishi K, Cox JA. Amino acid sequence of crayfish troponin I. J Biol Chem. 1989;264(3):1551-1557.

149. Zhu L, She T, Zhang Y, et al. Identification and characterization of ovary development-related protein EJO1 (Eri s 2) from the ovary of Eriocheir sinensis as a new food allergen. Mol Nutr Food Res. 2016;60(10):2275-2287.

150. Niggemann B, Beyer K. Diagnosis of food allergy in children: toward a standardization of food challenge. J Pediatr Gastroenterol Nutr. 2007;45(4):399-404.

151. Lopata AL, Andreas L, Kamath S. Shellfish allergy diagnosis - gaps and needs. Curr Allergy Clin Immunol. 2012;25(2):60-66.

152. Thermo Fisher Scientific. Allergen testing products: fish. Available from: http:/www.phadia.com/en/Products/Allergy-testing-products/ ImmunoCAP-Allergen-Information/Food-of-Animal-Origin/Fish/ Anchovy/. Accessed May 22, 2018.

153. Leung PSC, Chu KH. cDNA cloning and molecular identification of the major oyster allergen from the Pacific oyster Crassostrea gigas. Clinical Experimental Allergy 2001;31:1287-1294.

154. Asturias JA, Eraso E, Arilla MC, Gómez-Bayón N, Inácio F, Martínez A. Cloning, Isolation, and IgE-Binding Properties of Helix aspersa (Brown Garden Snail) Tropomyosin. International Archives of Allergy and Immunology 2002;128:90-96.

155. Rolland JM, Varese NP, Abramovitch JB, Anania J, Nugraha R, Kamath S, et al. Effect of Heat Processing on IgE Reactivity and CrossReactivity of Tropomyosin and Other Allergens of Asia-Pacific Mollusc Species: Identification of Novel Sydney Rock Oyster Tropomyosin Sac g 1. Molecular Nutrition \& Food Research 2018;62:1800148.

156. Miyazawa H, Fukamachi H, InagakiY, Reese G, Daul CB, Lehrer SB, et al. Identification of the first major allergen of a squid (Todarodes pacificus). Journal of Allergy and Clinical Immunology 1996;98:948-953.

157. Chen H-L, Mao H-Y, Cao M-J, Cai Q-F, Su W-J, Zhang Y-X, et al. Purification, physicochemical and immunological characterization of arginine kinase, an allergen of crayfish (Procambarus clarkii). Food and Chemical Toxicology 2013;62:475-484. 
158. Shen Y, Cao M-J, Cai Q-F, Su W-J, Yu H-L, Ruan W-W, et al. Purification, cloning, expression and immunological analysis of Scylla serrata arginine kinase, the crab allergen. Journal of the Science of Food and Agriculture 2011;91:1326-1335.

159. Hu M-J, Liu G-Y, Yang Y, Pan T-M, Liu Y-X, Sun L-C, et al. Cloning, Expression, and the Effects of Processing on Sarcoplasmic-CalciumBinding Protein: An Important Allergen in Mud Crab. Journal of Agricultural and Food Chemistry 2017;65:6247-6257.
160. Kalyanasundaram A, Santiago TC. Identification and characterization of new allergen troponin $\mathrm{C}$ (Pen $\mathrm{m}$ 6.0101) from Indian black tiger shrimp Penaeus monodon. European Food Research and Technology 2014;240:509-515.

161. Yang Y, Zhang Y-X, Liu M, Maleki SJ, Zhang M-L, Liu Q-M, et al. Triosephosphate Isomerase and Filamin C Share Common Epitopes as Novel Allergens of Procambarus clarkii. Journal of Agricultural and Food Chemistry 2017;65:950-963.

\section{Publish your work in this journal}

The Journal of Asthma and Allergy is an international, peer-reviewed open access journal publishing original research, reports, editorials and commentaries on the following topics: Asthma; Pulmonary physiology; Asthma related clinical health; Clinical immunology and the immunological basis of disease; Pharmacological interventions and new therapies. This journal is included in PubMed. The manuscript management system is completely online and includes a very quick and fair peer-review system, which is all easy to use. Visit http://www. dovepress.com/testimonials.php to read real quotes from published authors.

Submit your manuscript here: https://www.dovepress.com/journal-of-asthma-and-allergy-journal 